\title{
Gaspar de Crayer bajo el prisma clasicista de Guido Reni. El Ecce Homo del convento de Santa Paula en Sevilla
}

\author{
Gaspar de Crayer within the Prism of Classicism of Guido Reni. \\ The Ecce Homo from the Convent of Santa Paula in Seville
}

\author{
Rafael Japón ${ }^{1}$ \\ Universidad Autónoma de Madrid
}

Resumen: En esta ocasión se presenta un desconocido Ecce Homo de Gaspar de Crayer, conservado en el convento de Santa Paula de Sevilla. Además, se pone de manifiesto la relación estilística entre las obras de temática religiosa de este pintor flamenco y las de Guido Reni, a cuyo círculo se atribuía este lienzo, así como la influencia que este modelo pudo ejercer en la escuela pictórica hispalense.

Palabras clave: Gaspar de Crayer; Guido Reni; Bartolomé Esteban Murillo; Sevilla; Siglo XVII; Relaciones culturales internacionales; Ecce Homo.

Abstract: An unknown Ecce Homo by Gaspar de Crayer, preserved in the convent of Santa Paula in Seville, is have presented. It also highlights the stylistic relationship between the religious-themed works of this Flemish painter and those of Guido Reni, to whose circle this canvas was attributed until now, as well as the influence it could have had on the Sevillian pictorial school.

Key Words: Gaspar de Crayer; Guido Reni; Bartolomé Esteban Murillo; Seville; Early Modern Age; International cultural relations; Ecce Homo.

I구 http://orcid.org/0000-0002-4203-2703 


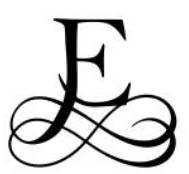

I menoscabo sufrido en el patrimonio de la ciudad de Sevilla a lo largo del tiempo por los diversos episodios bélicos, los expolios, las desamortizaciones y la venta descontrolada de bienes, no permiten apreciar en su dimensión real la riqueza monumental alcanzada allí en el Siglo de $\mathrm{Oro}^{2}$. Sin embargo, aún existen algunos lugares que afortunadamente se libraron, aunque solo en parte, de perder sus tesoros artísticos, como son los conventos de clausura. Probablemente por la propia condición de una casi completa incomunicación, algunos de estos edificios conservan todavía obras de arte prácticamente desconocidas que paulatinamente van mostrando al público. Uno de estos edificios es el convento de Santa Paula, en cuyas salas expositivas se conservan ejemplares pictóricos de gran interés, como un Ecce homo de excelente factura que ha llegado hasta hoy como obra anónima (Fig. 1). Aquí se propone relacionarlo con los pinceles del flamenco Gaspar de Crayer (1584-1669), a pesar de la fuerte influencia de Guido Reni.

\section{Un Ecce Homo entre el clasicismo boloñés y el naturalismo flamenco}

En este lienzo $(95 \times 73 \mathrm{~cm}$.) está representado Jesucristo, de más de medio cuerpo sentado, con las manos atadas y sosteniendo una caña, coronado de espinas y con las señales del escarnio. A diferencia de los modelos más difundidos, en esta ocasión no le acompaña ninguna otra figura tan habitual en esta temática, como las de Poncio Pilato y los sayones, sino que aparece aislado. Cristo se vuelve levemente en su torso para dirigir la mirada hacia el espectador. Con este recurso la imagen busca despertar un sentimiento de piedad y empatía en el fiel, que se potencia gracias a las lágrimas que brotan de sus ojos, las cuales siguen el mismo recorrido que los surcos de sangre que cae desde su frente. A pesar de ello, el artista alcanzó un resultado sereno y equilibrado, apoyándose además en un juego de contrastes lumínicos por el que la efigie, construida con tonalidades nacaradas, parece surgir de un fondo completamente oscuro, a excepción del halo que rodea su cabeza. Esa moderación lo acerca a ciertas propuestas de artistas clasicistas, tanto es así que, hasta el momento, solamente se había indicado que pudiera provenir del círculo de Guido Reni $(1575-1642)^{3}$.

\footnotetext{
2 Rocío Ferrín Paramio, El Alcázar de Sevilla en la Guerra de Independencia. El Museo napoleónico, (Sevilla: Patronato del Real Alcázar de Sevilla, 2009); Rafael Japón, "Una introducción a la fama y difusión de la obre de Murillo a través de las copias", en Bartolomé Esteban Murillo y la copia pictórica, ed. Rafael Japón, (Granada: Universidad de Granada, 2018), pp. 17-36. Agradezco a Ana DiéguezRodríguez la lectura de este texto y sus indicaciones, así como por facilitarme el estudio en el Instituto Moll, y a las religiosas del convento de Santa Paula de Sevilla.

3 Así está inventariado en la Guía Digital del Patrimonio Cultural de Andalucía, Instituto Andaluz del Patrimonio Histórico (IAPH), no inv. 14109100880281 (En web: https://quiadigital.iaph.es/bien/mueble/94609/sevilla/sevilla/ecce-homo, consultada: 18 de mayo de 2021).
} 


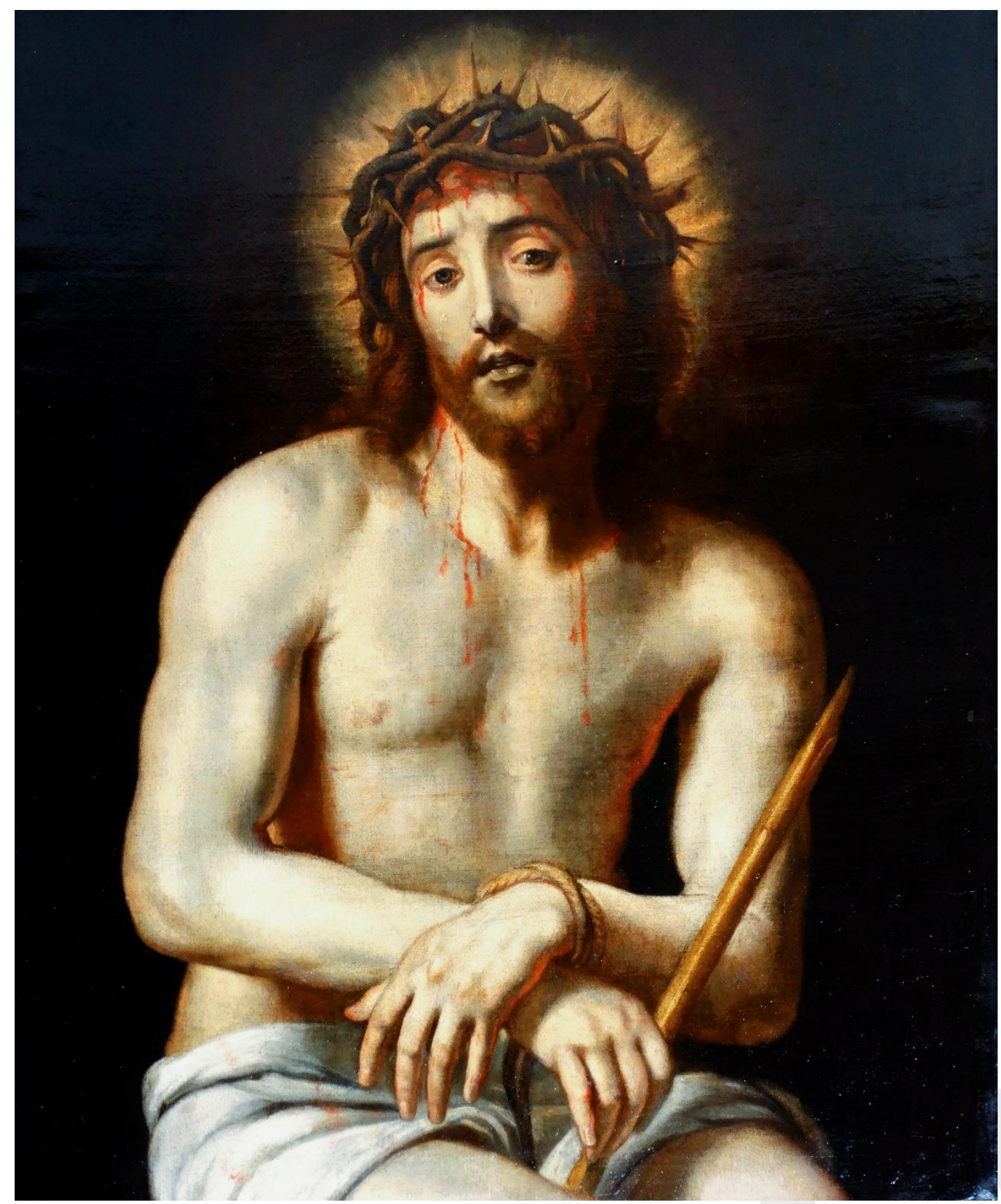

Fig. 1. Gaspar de Crayer, Ecce Homo, 1640-1656. Sevilla, Convento de Santa Paula, @) Foto: Rafael Japón.

El parecido entre este modelo y otras propuestas italianas pudo propiciar que se confundiera su autoría ya desde el siglo XVII. La analogía estilística con la obra de Reni pudo haber sido motivo suficiente para que en los inventarios se registrara con esa atribución, puesto que la producción de este pintor boloñés fue muy apreciada y más conocida en Sevilla que la de cualquier otro artista adscrito al clasicismo ${ }^{4}$. Abundando en este sentido, en

${ }^{4}$ Rafael Japón, "La presenza della pittura bolognese a Siviglia: collezionismo e influssi", en Dialogo artistico tra Italia e Spagna, ed. Marinella Pigozzi, (Bologna: Bononia University Press, 2018), pp. 27-38. 
el memorial de las pinturas que el arzobispo fray Domingo Pimentel tenía en el palacio arzobispal hispalense en 1650, el nombre de Reni se cita una decena de veces, estando entre ellos "un quadro con marcos dorados y dos cabezas pintadas de medio cuerpo, la una de Cristo coronado de espinas y la otra de nuestra Señora angustiada es copia de Guido Reni"5. A pesar de la confusa descripción del formato del cuadro, es posible que esta haga referencia a reproducciones de sendos originales conservados actualmente en la Galleria Nazionale d'Arte Antica di Palazzo Corsini'. Además, en el mismo repertorio aparecen con la misma iconografía: "Un quadro en que está pintado un Ecce homo de cuerpo entero atadas las manos"7, "Una lámina copia de un St. Ecce homo, con guarnición negra", y "Una lámina de un Ecce homo con una diadema" ${ }^{\prime 8}$. Por si fueran pocos los ejemplares con esta temática, se suma otro de gran interés para este estudio: "un quadro de un Santo Christo coronado de espinas con dos cabeças de angeles a los lados, la guarniçion dorada es copia de Caravachio" ${ }^{\prime 2}$. Hasta el momento no ha sido identificado ningún cuadro con estas características que pueda adscribirse a Michelangelo Merisi da Caravaggio (1571-1610), conociéndose por el contrario las propuestas de los pintores boloñeses de la primera mitad del siglo XVII, como Annibale Carracci (1560-1609) y Francesco Albani (1578-1660), así como otra de Gaspar de Crayer ${ }^{10}$. Cabe mencionar que en el siglo XIX se documenta en Sevilla un Ecce Homo de Reni en la colección de Aniceto Bravo ${ }^{11}$, y otro supuestamente salido de los pinceles de una de sus seguidoras, Elisabetta Sirani (1637-1665), en la residencia del deán Manuel López Cepero ${ }^{12}$, pero ninguno de los mencionados parece corresponder con la obra analizada en esta ocasión.

Si bien el autor de este cuadro supo captar la esencia de la pintura religiosa de Reni, coexisten una serie de particularidades que lo apartan de su producción. En primer lugar, se aprecia una técnica pictórica diferente, con el uso de unas pinceladas levemente más sueltas y una paleta de tonalidades más crudas, que dan como resultado una obra sutilmente más alejada de la idealización con la que el boloñés elaboró sus personajes sagrados. Ese mayor verismo se distingue además en la propia configuración de Cristo que mira al espectador, estableciendo un mismo nivel espacial entre la pintura y la realidad, siendo este un recurso que Reni

Rafael Japón, "Guido Reni's influence in Seville through originals, copies and prints", en Artistic circulation between early modern Spain and Italy, ed. Kelley Helmstutler Di Dio y Tommaso Mozzati, (New York; Londres: Routledge, 2020), pp. 173-191.

${ }^{5}$ Archivio Segreto Vaticano (ASV), Vescovi 25, f. 417r.

${ }^{6}$ Rafael Japón, "Murillo copista de copias italianas en la Sevilla del siglo XVII: la colección del arzobispo fray Domingo Pimentel", en Bartolomé Esteban Murillo y la copia pictórica, ed. Rafael Japón, (Granada: Universidad de Granada, 2018), p. 64.

7 ASV, Vescovi 25, f. 417v.

${ }^{8}$ ASV, Vescovi 25, f. 418r.

${ }^{9}$ ASV, Vescovi 25, f. 417r.

10 Japón, "Murillo copista de copias", pp. 97-98. En 2020 se subastó un Ecce homo rodeado de ángeles, atribuido al periodo juvenil de Antonio de Pereda (1611-1678), que recuerda a la versión de Crayer; Segre Subastas, Madrid, Pintura y escultura (14 de julio de 2020, lot. no 87).

11 José Amador de los Ríos, Sevilla pintoresca, (Sevilla: Francisco Álvarez y Ca, 1844), p. 441.

12 Vicente Álvarez Miranda, Glorias de Sevilla, (Sevilla: Carlos Santigosa, 1849), p. 143. 


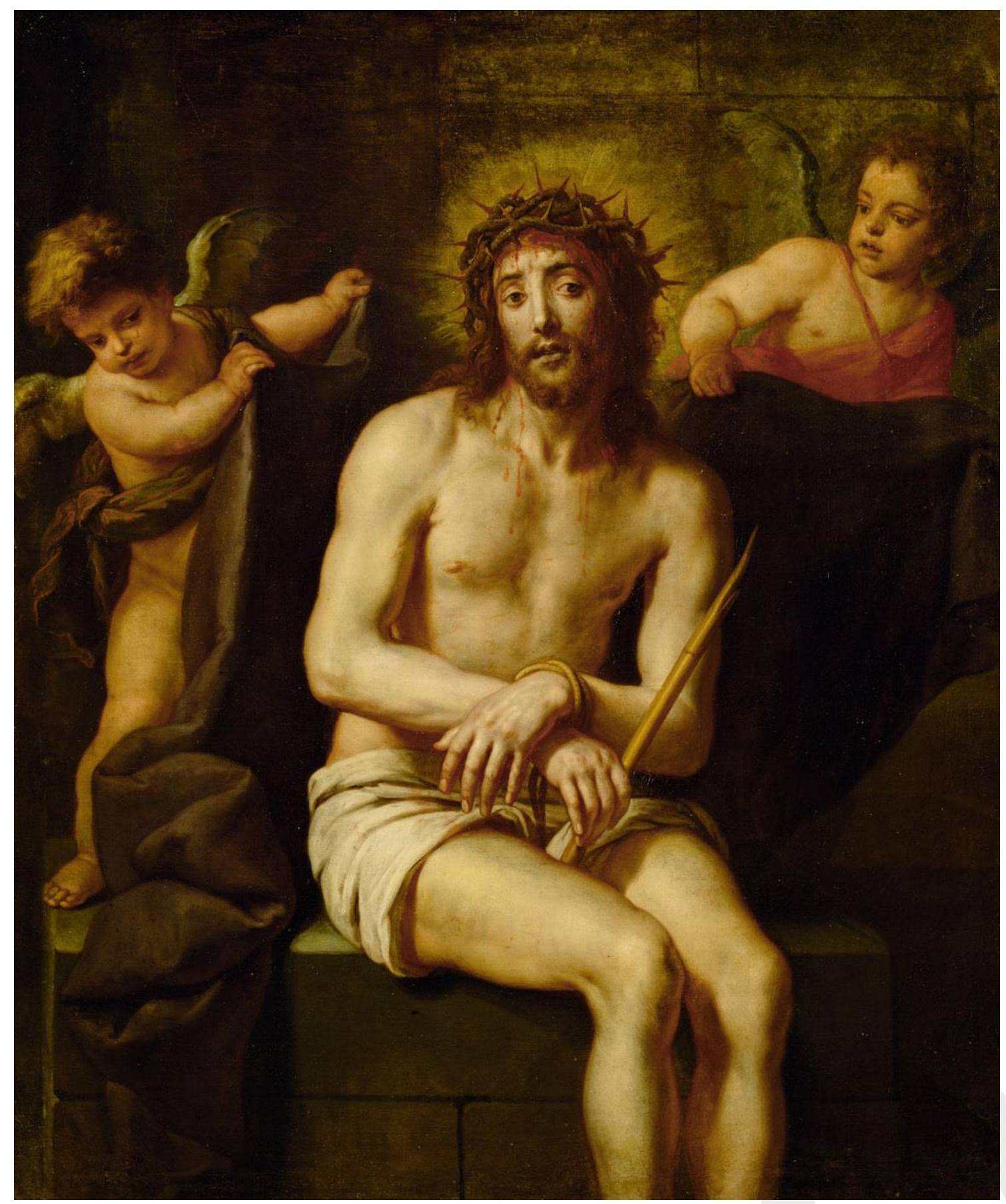

Fig. 2. Gaspar de Crayer, Ecce Homo con ángeles, 1640-1656. Viena, (C) Gemäldegalerie, Kunsthistorisches Museum.

parecía evitar para mantener la distancia entre lo divino y lo terreno, como puede apreciarse en todos los cuadros que realizó con este tema. En este sentido, se conocen distintas versiones del Ecce Homo creadas por el artista boloñés, siendo la composición más difundida aquella en la que se efigia solamente la cabeza de Jesucristo en un formato ovalado ${ }^{13}$. Por otro lado, también llevó a cabo otras de media figura, destacando un lienzo que se conservaba en la Gemäldegalerie de Dresde - desaparecido como

${ }^{13}$ Véase, por ejemplo, el ejemplar conservado en Paris, Musée du Louvre (inv. no 528). 
consecuencia de los acontecimientos bélicos del siglo pasado -, así como otro expuesto en el Fitzwilliam Museum de Cambridge. En este último, no solo dispuso la mirada del protagonista lejos del espectador, sino que también orientó su cuerpo desplazado en relación al espectador, lo que acrecienta la sensación de distanciamiento entre ambos.

No obstante, este particular naturalismo de estirpe flamenca sitúa a este lienzo dentro de la producción de Gaspar de Crayer, siendo esta, por tanto, su única obra localizada hasta el momento en los territorios hispalenses. En esta composición, el pintor está retomando la parte central de otro Ecce Homo suyo que se conserva en la Gemäldegalerie del Kunsthistorisches Museum de Viena (inv. no Gemäldegalerie, F.15), (Fig. 2). Este último se trata de una versión de mayores proporciones $(147,5 \times 121,3 \mathrm{~cm})$, en la que la figura de Cristo, construida casi de cuerpo entero, está flanqueada por dos ángeles volanderos en actitud de arroparlo con un manto. Con la inclusión de este gesto, el pintor se aparta de la literalidad del pasaje bíblico en el que se basa este asunto, pues según el Evangelio de Mateo (Mt. 27, 27-29) fueron los soldados del gobernador de Judea quienes lo desnudaron y lo vistieron con un manto, además de colocarle la corona de espinas en la cabeza y la caña en la mano derecha. Esta licencia compositiva no es original de Crayer, sino que existen diversos precedentes ligados especialmente al arte nórdico del siglo anterior, como es el Ecce Homo de Hans Schaüfelein (c. $1480 / 85-$ c.1538/40) ${ }^{14}$, aunque también se dieron algunos ejemplos en el ámbito italiano, como demuestra el cuadro de Alessandro Bonvicino, conocido como Moretto da Brescia (c. 1498-1554), conservado en la Pinacoteca Tosio Martinengo de Brescia. De esta manera, el pintor reinterpreta este episodio atenuando la violencia narrada en las Sagradas Escrituras, al prescindir de los sayones que se burlaron de Jesús. Por el contrario, en su lugar aparecen dos ángeles que están colocándole el manto, transformando por completo el significado de este acto, prevaleciendo así un mensaje sobre la omnipresente misericordia de Dios. Por tanto, si la imagen del Ecce Homo expone ante el espectador la naturaleza mortal de Cristo, con esta nueva interpretación se alude a su indiscutible doble condición humana y divina. Por otro lado, la presencia de estos dos personajes atenúa el carácter dramático y profundamente reflexivo de esta iconografía, debido principalmente a la gracia con la que Crayer los representó.

Esto puede llevar a pensar que el cuadro de Sevilla fuera concebido en origen como una reproducción autógrafa y que hubiera sido recortado posteriormente, pero ni siquiera un atento análisis visual de la tela permite confirmar esta hipótesis. Por el contrario, parece que el autor versionó su propia obra aislando a Cristo, puesto que la amplitud del brillo del halo se circunscribe solamente a su cabeza, mientras que en el cuadro de Viena se proyecta más allá en el fondo, iluminando el brazo de uno de los ángeles,

${ }^{14}$ Se trata de una composición conocida a través del grabado. Existe un ejemplar en Dresde, Staatliche Kunstsammlungen, (inv. nº A 2096). 
que en el lienzo sevillano es imperceptible. Cabe destacar la existencia de una copia completa de la pintura austriaca, de dimensiones algo reducidas, en una colección particular de Amberes, la cual se atribuye igualmente a Crayer ${ }^{15}$.

Por tanto, se deduce que este modelo debió de gozar de cierto éxito, por lo que el artista llevaría a cabo diversas versiones para cumplir con sus encargos. Tanto es así que el cuadro de Viena estaba en 1659 en la colección del archiduque Leopoldo Guillermo de Habsburgo, para quien Crayer trabajaba como pintor de cámara. Esta sirvió en la decoración de la Hofburgkapelle - la Capilla Imperial de Viena -, aunque se fecha en años anteriores, entre 1640 y $1656^{16}$. Las similitudes técnicas y estilísticas existentes entre las versiones conocidas permiten datar la obra sevillana en esos mismos años, aunque no es posible precisar con certeza cuando llegaría a la capital andaluza.

El único personaje relacionado con la curia sevillana que se cree que pudo haber tenido algún vínculo con la producción de Crayer fue el arzobispo Gaspar de Borja y Velasco, quien antes de ocupar su cargo en la archidiócesis hispalense estuvo hasta 1635 en Roma, donde fue nombrado cardenal y arzobispo de Albano. En la catedral de esta última localidad de la región del Lacio se conserva una Piedad del pintor flamenco cuyo origen pudo deberse a la acción de mecenazgo que Borja ejerció en los lugares en los que tuvo alguna responsabilidad ${ }^{17}$. Si bien esta información es por el momento una hipótesis, se conoce que otro miembro de la familia Borja, Magdalena Francisca Luisa Esperanza de Borja y Doria, junto con su esposo el I duque de Arenberg, encargaron a Crayer una pintura con la representación de la Caritas romana en $1645^{18}$. Este artista fue también pintor de cámara del cardenal-infante Don Fernando de Austria, hermano de Felipe IV, pasando a la muerte de este noble a servir al propio monarca ${ }^{19}$, lo

\footnotetext{
${ }^{15}$ Esta otra copia procede del colegio jesuita de Nuestra Señora (Onze-Lieve-Vrouwecollege) de Amberes y fue vendida en subasta en 1998; véase: Veilinghuis Bernaerts (Amberes) 1998-03-30, n.o 71 (En web: https://rkd.nl/en/explore/images/40145, consultada: 18 de mayo de 2021); Entre Rubens et Van Dyck, Gaspar de Crayer (1584-1669), ed. Sandrine Vézilier-Dussart y Alexis Merle Du Bourg, (Gante: Snoeck, 2018), p. 98, nota 3. Además, el conde Ferdinand de Hohenzollern poseía en Colonia una copia del Ecce homo de Crayer como se deduce del catálogo de la subasta de su colección: Catalogue D'un Cabinet de Tableaux, Tres bien conservés, partie de Maitres Italiens, partie de maitres Flamands, le tout en cadres, proprement dorés, \& artistement travaillés dans le gout François, delaissé par feu S.E. Mons. le Comte Ferdinand de Hohenzollern, (Colonia: chez Schauberg, 1748), lot. n. ${ }^{0} 242$. En fechas posteriores se vendieron como originales otros dos Ecce Homo de este mismo artista, uno en 1781 en París (véase: Catalogue d'une très-belle et riche collection de tableaux des trois écoles, provenant d'un cabinet étranger, (París: Chez Valée de Clerville, 1781), p. 15, n. ${ }^{\circ} 95$, y otro en Londres en 1814; Christie's, Pall Mall, (28 de mayo, lot. n. ${ }^{1}$ 125).

16 Hans Vlieghe, Gaspar de Crayer, sa vie et ses oeuvres, (Bruselas: Arcade, 1972), tomo 2, p. 230; Entre Rubens et Van Dyck, Cat. Exp., 2018, p. 98.

17 David García Cueto, "La acción cultural y el mecenazgo de los cardenales-embajadores de Felipe IV en Roma: Borja y Albornoz", en I rapporti tra Roma e Madrid nei secoli XVI e XVII, ed. Alessandra Anselmi, (Roma: Gangemi, 2014), p. 146.

18 Vlieghe, Gaspar de Crayer, tomo 2, p. 313; Matías Díaz Padrón, "Un nuevo lienzo de Gaspar de Crayer en España: 'Caritas Romana'", Boletín del Museo e Instituto Camón Aznar, 104, (2009), pp. 75-88.

19 Matías Díaz Padrón, "Gaspar de Crayer un pintor de retratos de los Austria", Archivo Español de Arte, 151, 38, (1965), pp. 229-244; M. Díaz Padrón, "Algunos retratos más de Gaspar de Crayer", Archivo Español de Arte, 151, 38, (1965), pp. 291-299.
} 


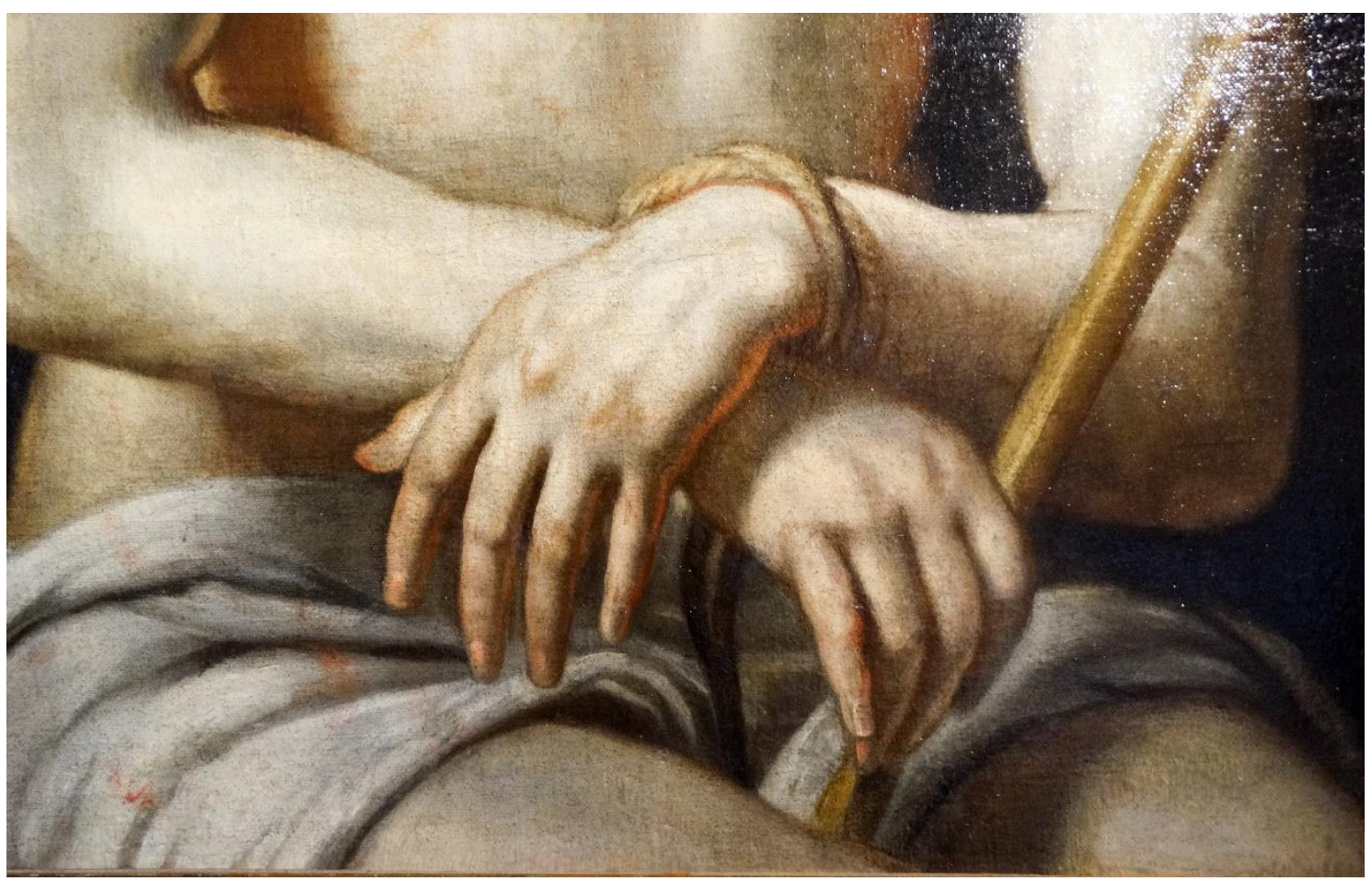

Fig. 3. Gaspar de Crayer, Ecce Homo, (detalle) 1640-1656. Sevilla, Convento de Santa Paula. (Particular), (C) Foto: Rafael Japón.

que propiciaría una predilección en la corte por sus obras, siendo quizás alguno de sus miembros quien la enviara a Sevilla.

\section{La influencia de Guido Reni en la producción de Crayer}

Esta no fue la única creación en la que el pintor flamenco demostró conocer en profundidad el estilo de Guido Reni. Sus imágenes devocionales están colmadas de referencias a sus composiciones, tanto es así que en diversas ocasiones han sido erróneamente atribuidas al taller del boloñés, como sucedió con el San Jerónimo en meditación del Museo Nacional de San Carlos $^{20}$. Asimismo, se conoce que su admiración le llevaría a copiar algunos de sus cuadros, como una Judit y Holofernes que en 1618 se hallaba en la colección de Melchior Wijntgis, actualmente en paradero desconocido ${ }^{21}$, y una Aparición de la Virgen con el Niño a San Felipe Neri que sigue de manera fiel el original que se halla en la iglesia de Santa Maria in Vallicella en Roma. Esta última reproducción de Crayer se conserva en la actualidad en la iglesia de Notre-Dame du Finistère de Bruselas, siendo concebida en un formato de mayores dimensiones que el original ${ }^{22}$. Sin duda, el pintor debió conocer el éxito del que gozaban las obras de Reni tanto en el

\footnotetext{
20 Vlieghe, Gaspar de Crayer, tomo 2, p. 133.

${ }^{21}$ Vlieghe, Gaspar de Crayer, tomo 2, p. 76.

22 Vlieghe, Gaspar de Crayer, tomo 2, pp. 202.203. El autor propone que Crayer tuviera una copia pictórica de la obra de Reni delante suya cuando llevaba a cabo su reproducción.
} 
Vaticano como en las diversas cortes europeas - incluida la española ${ }^{23}$-, puesto que había conseguido crear una serie de imágenes en perfecta consonancia con los valores de la Contrarreforma. La influencia del clasicismo romano-boloñés se dio también en la pintura de otros artistas, como Diego Velázquez (1599-1660) y Bartolomé Esteban Murillo (1617$1682)^{24}$, por lo que debería considerarse como una característica que se suma a las planteadas por Díaz Padrón al explicar las afinidades entre sus estilos $^{25}$. Por otro lado, el conocimiento que este flamenco poseyó de la pintura italiana debió ser aún más amplio, pues se ha señalado que también manejaba planteamientos compositivos y estilísticos de maestros tan dispares como Tiziano (c.1490-1576), Fra Bartolomeo (1472-1517) y Caravaggio $^{26}$.

Así lo demuestra en algunas de las obras devocionales que llegaron a España, como los lienzos de grandes dimensiones que formaron parte de la decoración del monasterio de San Francisco de Burgos. En origen se cree que fueron diecisiete piezas, encargadas por Don Miguel de Salamanca, aunque no todas han llegado hasta la actualidad, conservándose seis de ellas en el Museo Nacional del Prado con las efigies de San Juan Bautista, San Agustín, San Ambrosio, San Antonio de Padua con el Niño, San Pedro Nolasco y Santo Domingo de Guzmán, fechados en los mismos años que el Ecce Homo de Viena ${ }^{27}$. En la pinacoteca madrileña existen además otros dos ejemplares de temática religiosa, como una versión diferente de la Caridad romana citada anteriormente, y La aparición de la Virgen a Simón de Rojas $^{28}$. No obstante, un ejemplo claro de su relación con la pintura italiana es un lienzo con el Bautismo de Cristo, que se halla en el monasterio de las Descalzas Reales de Madrid, el cual estuvo considerado como anónimo italiano hasta 2004, cuando Díaz Padrón lo devolvió al catálogo de Crayer ${ }^{29}$. Además, este mismo especialista dio a los pinceles del flamenco una pintura con Tobías y el ángel, perteneciente a una colección particular madrileña, que se atribuía a Juan Bautista Maíno (1581-1649) ${ }^{30}$. Jusepe Martínez sitúa a este pintor español en Roma como compañero de Reni imitando su estilo, de la siguiente manera: "Pocos años atrás floreció un lucidísimo ingenio

\footnotetext{
23 José Luis Colomer, "Guido Reni en las colecciones reales españolas" en España y Bolonia: siete siglos de relaciones artísticas y culturales, ed. José Luis Colomer y Amadeo Serra Desfilis, (Madrid: Centro de Estudios Europa Hispánica, 2006), pp. 213-240.

24 Japón, "La presenza della pittura", pp. 27-38.

25 Díaz Padrón, "Gaspar de Crayer un pintor", pp. 234-235.

${ }^{26}$ Vlieghe, Gaspar de Crayer, tomo 2, p. 63.

27 Díaz Padrón, "Gaspar de Crayer un pintor", pp. 234-235; M. Díaz Padrón, "Gaspar de Crayer en el monasterio de San Francisco de Burgos", Archivo Español de Arte, 161, 41, (1968), pp. 17-28; M. Díaz Padrón, "Miguel de Salamanca, a client of Gaspar de Crayer (1584-1669) at the Monastery of San Francisco, Burgos", RBAHA, 85, (2016), pp. 5-28.

28 Matías Díaz Padrón, "Nuevas pinturas de Gaspar de Crayer en España: La aparición de la Virgen a Fray Simón de Rojas y Don Juan José de Austria a caballo", Arte Español-Revista Española de Arte, 25, (1963-1967), pp. 154-162. María Cruz de Carlos Varona, "La Aparición de la Virgen a Simón de Rojas de Gaspar de Crayer: Origen y contexto de una obra del Museo del Prado", en In sapientia libertas: escritos en homenaje al profesor Alfonso E. Pérez Sánchez, ed. Museo Nacional del Prado, (Madrid: Museo Nacional del Prado; Sevilla: Fundación Focus-Abengoa, 2007), pp. 334-341.

29 Matías Díaz Padrón, "Un lienzo inédito del Bautismo de Cristo de Gaspar de Crayer, en las Descalzas Reales de Madrid", Reales Sitios, 160, (2004), pp. 68-71.

30 Matías Díaz Padrón, "Una nueva versión de Tobías y el ángel de Gaspar de Crayer en Madrid", Tendencias del mercado del arte, 102, (2017), pp. 76-78.
} 
llamado Fr. Juan Bautista Maíno, discípulo y amigo que fue de Anibal Caracho (Carracci), y gran compañero de nuestro gran Guido Reni, que siguió siempre su manera de pintar"31. Otra razón a considerar sobre la adhesión de Crayer a las tendencias clasicista es la proximidad al estilo de artistas flamencos que estuvieron en Italia, como Van Dyck, dependencia que se evidencia en otras de sus obras que llegaron a España, como la Lamentación sobre Cristo muerto de la catedral de Vitoria-Gasteiz.

\section{Difusión, concomitancias e influencias del Ecce Homo de Crayer en España}

En el Ecce Homo sevillano, como en otros ejemplares, Crayer alcanza un resultado estético que guarda cierta analogía con la pintura española de mediados del siglo XVII, como la de Velázquez, pudiéndose explicar estas afinidades por un conocimiento común de Rubens (1577-1640) y Van Dyck (1599-1641) ${ }^{32}$. Sea como fuere, estas semejanzas visuales que se intuyen especialmente en detalles relativos a la manera de construir la figura, como la definición de los contornos y la aplicación de suaves pinceladas (Fig. 3), se ajustaron perfectamente al panorama pictórico hispalense. Además, en esta ciudad la pintura flamenca era muy apreciada desde la centuria anterior $^{33}$, por lo que este ejemplar debió ser admirado allí incluso por otros artistas.

En este sentido, es muy probable que esta original composición sirviera de inspiración a otros pintores interesados en temas devocionales, como puede ser Murillo, en cuya producción se cuenta con numerosas versiones de esta iconografía, las cuales fueron ampliamente difundidas a través del copiado $^{34}$. En el Museo de Bellas Artes de Murcia existe una obra dada con seguridad a los pinceles de Murillo ${ }^{35}$ (Fig. 4), para la cual debió tomar como modelo la obra de Crayer. El sevillano tradujo a su particular estilo esta composición en la que se aprecia la figura de Cristo en soledad, sentado en un banco de piedra, con los mismos atributos, sobre un fondo neutro de un modo semejante a como aparece en la tela aquí analizada. No obstante, Murillo introdujo notables diferencias, como el manto que cubre su regazo, la dirección de su mirada, así como la interpretación del cuerpo hasta los pies. Esta última discrepancia con la obra de Crayer la acerca más bien a la versión conservaba en Viena, por lo que podría deducirse que el lienzo sevillano pudo haber sido sometido a un recorte por su parte inferior. Esto

\footnotetext{
31 Jusepe Martínez, Discursos practicables del nobilísimo arte de la pintura, ed. Valentín Carderera y Solano, (Madrid: Imprenta de Manuel Tello, 1866), pp. 120-121.

32 Díaz Padrón, "Gaspar de Crayer un pintor", pp. 234-235; M. Díaz Padrón, "Gaspar de Crayer en el monasterio", pp. 18-19.

${ }^{33}$ Enrique Valdivieso, "Pintura flamenca de los siglos XVI y XVII en Sevilla", en La senda española de los artistas flamencos, ed. Museo Nacional del Prado, (Madrid: Fundación Amigos del Museo del Prado; Barcelona: Galaxia Gutenberg Círculo de Lectores, 2009), pp. 233-247.

${ }^{34}$ La relación entre Murillo y ciertas obras de Crayer conservadas en España fue también puesta de relieve en: Matías Díaz Padrón, "Gaspar de Crayer en el monasterio", pp. 27-28.

35 Diego Angulo Íñiguez, Murillo, (Madrid: Espasa-Calpe, 1981), tomo 2, p. 220.
} 


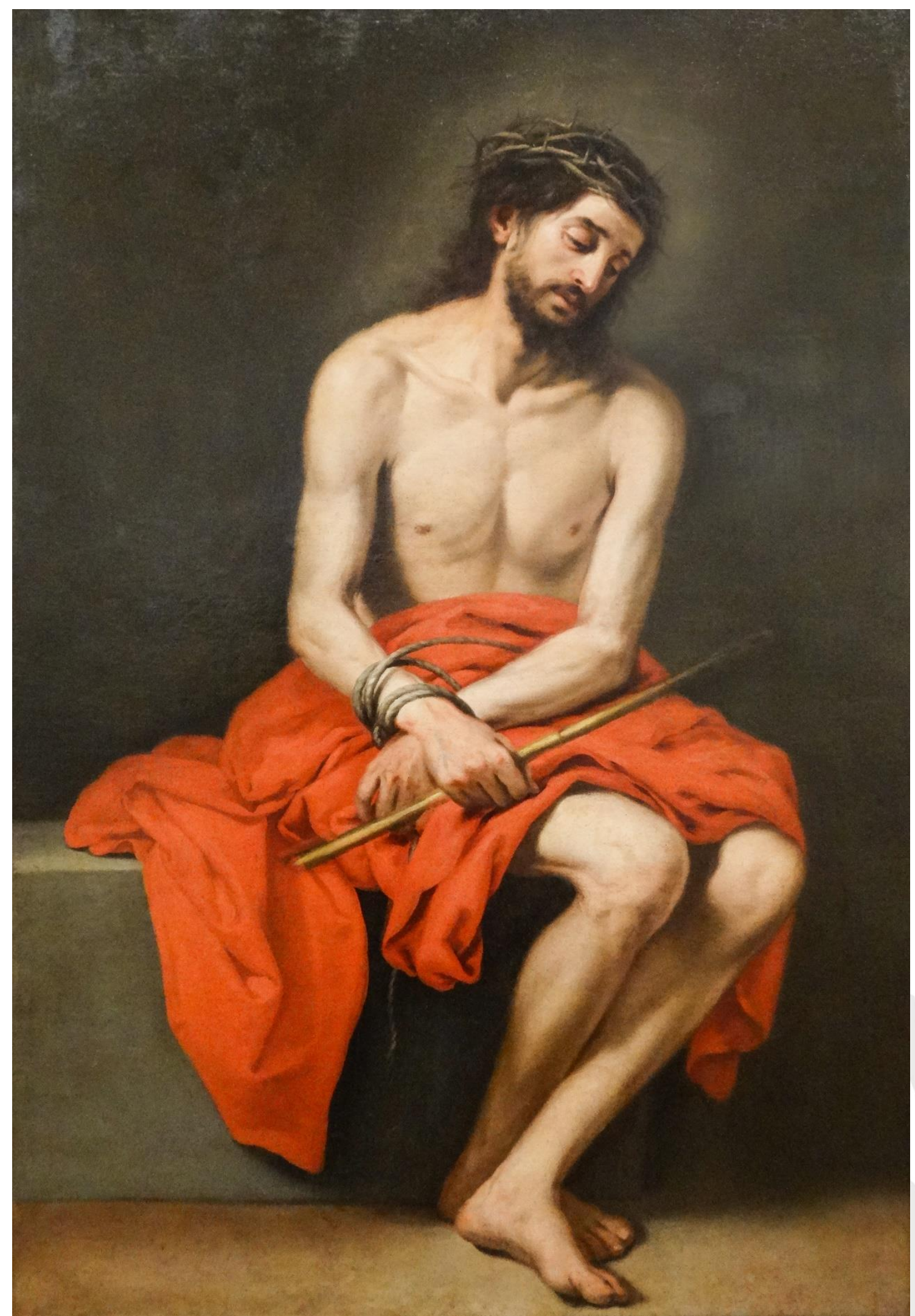

Fig. 4. Bartolomé Esteban Murillo, Ecce Homo, c. 1670. Murcia, Museo de Bellas Artes, @Foto: Rafael Japón. 
explicaría también la anómala conclusión de la figura por encima de las rodillas, que se traduce en un cierto desequilibrio compositivo.

Por otra parte, resulta llamativo que Murillo modificara la dirección de la mirada de Cristo, apartándola del contacto directo con el espectador, dulcificando así la experiencia de su contemplación. Precisamente, este rasgo de interacción con el fiel, en la obra de Crayer se ha interpretado como un valor añadido a la devoción militante e intensa que reflejaba en sus pinturas religiosas asociadas a la Pietas Austriaca, tan defendida por el Archiduque Leopoldo ${ }^{36}$. En cambio, Murillo prefirió representar al Ecce Homo en numerosas variantes, pero siempre evitando colocar la mirada frente al espectador siguiendo más bien otros modelos italianos, como los de Tiziano y Guido Reni, los cuales también pudo ver en Sevilla ${ }^{37}$. Sin embargo, existe una versión conservada en la Galería Nacional de Eslovenia en la que el sevillano parece reinterpretar nuevamente la pintura de Crayer (Fig. 5), esta vez de medio cuerpo y con la cabeza en idéntica posición, aunque dirigiendo sutilmente la mirada al plano inferior del espacio de quien lo observa. Por supuesto, se trata de una imagen mucho más sosegada, en la que no brota sangre de las heridas, Cristo está parcialmente cubierto por una túnica y se sitúa en una suerte de hornacina ${ }^{38}$.

Por tanto, si las afinidades visuales aquí presentadas demuestran un fenómeno de influencias directas entre ambas obras, eso indicaría que el lienzo de Crayer debió alcanzar la capital hispalense antes de la década de 1670, años en que se fechan estas versiones de Murillo. Aún así, no se tiene ninguna certeza documental de la entrada del cuadro al convento, ni siquiera de la presencia de otra tela de este pintor en la ciudad hasta este momento. En este sentido, en el siglo XVIII, se pensaba que la Lamentación sobre Cristo muerto de la catedral de Vitoria-Gasteiz procedía de Sevilla ${ }^{39}$, y entre las atribuciones dadas al lienzo por entonces estaba la de Murillo imitando el estilo de Anton Van Dyck ${ }^{40}$. No obstante, se trata de una obra de Crayer, que fue adquirida para la decoración de la capilla funeraria de la familia Galarreta en la colegiata de Vitoria, construida entre 1661 y $1663^{41}$.

\footnotetext{
${ }^{36}$ Entre Rubens et Van Dyck, Cat. Exp., 2018, p. 98.

37 Japón, "Murillo copista de copias", pp. 69-70.

38 Sobre este Ecce Homo de Murillo, véase: Pavel Štěpánek, "Španělská malba ze slovenských zbírek", Journal ARS, 39, (2006), pp. 53-76. Esta versión, a diferencia de la conservada en el Museo de Bellas Artes de Murcia, sí fue reproducida por su obrador, como demuestra una copia conservada en una colección particular de Barcelona; una fotografía de esta pintura se reproduce en: Enrique Valdivieso, La escuela de Murillo. Aportaciones al conocimiento de su discípulos y seguidores, (Sevilla: Universidad de Sevilla, Ayuntamiento de Sevilla, ICAS, 2018), p. 367.

39 Julio-César Santoyo, Viajeros por Álava (siglos XV a XVIII), (Vitoria: Obra Cultural de la Caja de Ahorros Municipal de Vitoria, 1972), pp. 180-181.

40 Guía de forasteros en Vitoria por lo respectivo a las tres Bellas artes de pintura, escultura y arquitectura, con otras noticias curiosas que nacen de ellas, (Vitoria: Baltasar Manteli, 1792), p. 19.

${ }^{41}$ Cristina Aransay Saura, "Restauración de la pintura 'Lamentación sobre Cristo muerto' atribuido al pintor Gaspar de Crayer", en Homenaje a Micaela Portilla Vitoria, Actas de las Jornadas Congresuales, (Vitoria: Sociedad de Estudios Vascos = Eusko Ikaskuntza, 2007), pp. 340-347; Fernando R. Bartolomé García, "Lamentación sobre Cristo muerto de la catedral de Santa María de Vitoria-Gasteiz atribuido a Gaspar de Crayer. Revisión y nuevas aportaciones", Espacio, tiempo y forma. Serie VII, Historia del arte, 24, (2011), pp. 153-179.
} 


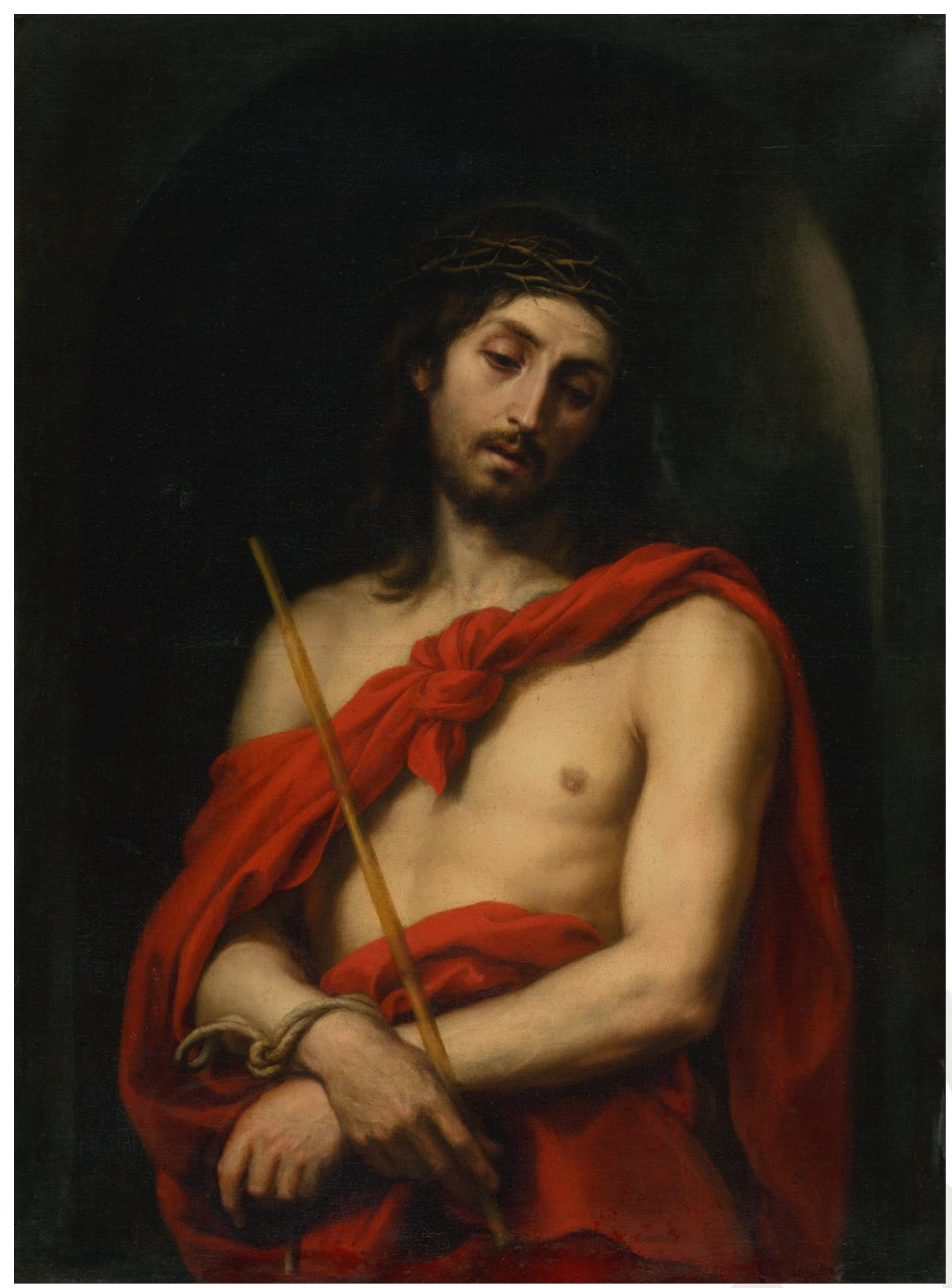

Fig. 5. Bartolomé Esteban Murillo, Ecce Homo, c. 1670. Bratislava: Galería Nacional de Eslovenia, () Foto: Slovenská národná galéria, SNG 


\section{Conclusiones}

La interesante combinación de influjos italianos y la vertiente clasicista tamizada por algunos maestros flamencos aquí planteada, se puede apreciar también en otros artistas españoles contemporáneos a Crayer, como Murillo, Juan Carreño de Miranda (1614-1685) y Mateo Cerezo (1637-1666) ${ }^{42}$. Por tanto, el Ecce Homo de Crayer en Sevilla permite reflexionar sobre un fenómeno de influencias artísticas en la pintura religiosa contrarreformista, por el que los límites tradicionales propuestos por la historiografía para las diversas escuelas europeas se desdibujan y carecen de sentido. En cambio, se atiende a unas semejanzas técnicas y expresivas entre artistas italianos, españoles y flamencos de un mismo periodo, que manifiestan una cierta predilección común y espontánea por unos modelos y estilos concretos. Especialmente aquellos de pintores cuyas obras fueron admiradas y solicitadas tanto en la curia papal como en las cortes occidentales a comienzos del siglo XVII. Entre estos, cobra especial relevancia Guido Reni, quien llegó a crear una imagen muy determinada de la nueva santidad postridentina, la cual se adscribiría no solo a los territorios italianos, sino a todo el orbe cristiano. Este éxito se extendió consecuentemente hacia un plano comercial, lo que llevaría a otros artistas a inspirarse en la producción del boloñés, integrándolo a otros influjos y al propio genio creativo, lo que en ocasiones ha llevado a confundir la autoría de obras de maestros de distintas nacionalidades, y a veces sin haberse probado algún vínculo entre ellos ${ }^{43}$.

42 Matías Díaz Padrón, "La influencia de Van Dyck en Carreño, Cerezo y Crayer", Galeria Anticuaria, no 109, (1995), pp. 32-37.

43 Díaz Padrón, "La influencia de Van Dyck", p. 37. 
Bibliografía:

Álvarez Miranda 1849: Vicente Álvarez Miranda, Glorias de Sevilla, (Sevilla: Carlos Santigosa, 1849).

Amador de los Ríos 1844: José Amador de los Ríos, Sevilla pintoresca, (Sevilla: Francisco Álvarez y Ca, 1844).

Angulo Íñiguez 1981: Diego Angulo Íñiguez, Murillo, (Madrid: Espasa-Calpe, 1981).

Aransay Saura 2007: Cristina Aransay Saura, "Restauración de la pintura 'Lamentación sobre Cristo muerto' atribuido al pintor Gaspar de Crayer", en Homenaje a Micaela Portilla Vitoria, Actas de las Jornadas Congresuales, (Vitoria: Sociedad de Estudios Vascos = Eusko Ikaskuntza, 2007), pp. 340347.

Bartolomé García 2011: Fernando R. Bartolomé García, "Lamentación sobre Cristo muerto de la catedral de Santa María de Vitoria-Gasteiz atribuido a Gaspar de Crayer. Revisión y nuevas aportaciones", Espacio, tiempo y forma. Serie VII, Historia del arte, 24, (2011), pp. 153-179.

Carlos Varona 2007: María Cruz de Carlos Varona, "La Aparición de la Virgen a Simón de Rojas de Gaspar de Crayer: Origen y contexto de una obra del Museo del Prado", en In sapientia libertas: escritos en homenaje al profesor Alfonso E. Pérez Sánchez, ed. Museo Nacional del Prado, (Madrid: Museo Nacional del Prado; Sevilla: Fundación Focus-Abengoa, 2007), pp. 334-341.

Catalogue 1748: Catalogue D'un Cabinet de Tableaux, Tres bien conservés, partie de Maitres Italiens, partie de maitres Flamands, le tout en cadres, proprement dorés, \& artistement travaillés dans le gout François, delaissé par feu S.E. Mons. le Comte Ferdinand de Hohenzollern, (Colonia: chez Schauberg, 1748).

Catalogue 1781: Catalogue d'une très-belle et riche collection de tableaux des trois écoles, provenant d'un cabinet étranger, (París: Chez Valée de Clerville, 1781).

Colomer 2006: José Luis Colomer, "Guido Reni en las colecciones reales españolas" en España y Bolonia: siete siglos de relaciones artísticas y culturales, ed. José Luis Colomer y Amadeo Serra Desfilis, (Madrid: Centro de Estudios Europa Hispánica, 2006), pp. 213-240.

Díaz Padrón 1963-1967: Matías Díaz Padrón, "Nuevas pinturas de Gaspar de Crayer en España: La aparición de la Virgen a Fray Simón de Rojas y Don Juan José de Austria a caballo", Arte Español-Revista Española de Arte, 25, (1963-1967), pp. 154-162.

Díaz Padrón 1965: Matías Díaz Padrón, "Algunos retratos más de Gaspar de Crayer", Archivo Español de Arte, 151, 38, (1965), pp. 291-299. 
Díaz Padrón 1965: Matías Díaz Padrón, "Gaspar de Crayer un pintor de retratos de los Austria", Archivo Español de Arte, 151, 38, (1965), pp. 229244.

Díaz Padrón 1968: Matías Díaz Padrón, "Gaspar de Crayer en el monasterio de San Francisco de Burgos", Archivo Español de Arte, 161, 41, (1968), pp. 17-28.

Díaz Padrón 1995: Matías Díaz Padrón, "La influencia de Van Dyck en Carreño, Cerezo y Crayer", Galería Anticuaria, n. ${ }^{2}$ 109, (1995), pp. 32-37.

Díaz Padrón 2004: Matías Díaz Padrón, "Un lienzo inédito del Bautismo de Cristo de Gaspar de Crayer, en las Descalzas Reales de Madrid", Reales Sitios, 160, (2004), pp. 68-71.

Díaz Padrón 2009: Matías Díaz Padrón, "Un nuevo lienzo de Gaspar de Crayer en España: 'Caritas Romana'", Boletín del Museo e Instituto Camón Aznar, 104, (2009), pp. 75-88.

Díaz Padrón 2016: Matías Díaz Padrón, "Miguel de Salamanca, a client of Gaspar de Crayer (1584-1669) at the Monastery of San Francisco, Burgos", RBAHA, 85, (2016), pp. 5-28.

Díaz Padrón 2017: Matías Díaz Padrón, "Una nueva versión de Tobías y el ángel de Gaspar de Crayer en Madrid", Tendencias del mercado del arte, 102, (2017), pp. 76-78.

Ferrín Paramio 2009: Rocío Ferrín Paramio, El Alcázar de Sevilla en la Guerra de Independencia. El Museo napoleónico, (Sevilla: Patronato del Real Alcázar de Sevilla, 2009).

Gante 2018: Entre Rubens et Van Dyck, Gaspar de Crayer (1584-1669), ed. Sandrine Vézilier-Dussart y Alexis Merle Du Bourg, (Gante: Snoeck, 2018).

García Cueto 2014: David García Cueto, "La acción cultural y el mecenazgo de los cardenales-embajadores de Felipe IV en Roma: Borja y Albornoz", en I rapporti tra Roma e Madrid nei secoli XVI e XVII, ed. Alessandra Anselmi, (Roma: Gangemi, 2014), pp. 340-361.

Guía 1792: Guía de forasteros en Vitoria por lo respectivo a las tres Bellas artes de pintura, escultura y arquitectura, con otras noticias curiosas que nacen de ellas, (Vitoria: Baltasar Manteli, 1792).

Japón 2018: Rafael Japón, "Una introducción a la fama y difusión de la obra de Murillo a través de las copias", en Bartolomé Esteban Murillo y la copia pictórica, ed. Rafael Japón, (Granada: Universidad de Granada, 2018), pp. 17-36.

Japón 2018: Rafael Japón, "Murillo copista de copias italianas en la Sevilla del siglo XVII: la colección del arzobispo fray Domingo Pimentel", en Bartolomé Esteban Murillo y la copia pictórica, ed. Rafael Japón, (Granada: Universidad de Granada, 2018), pp. 55-118. 
Japón 2018: Rafael Japón, "La presenza della pittura bolognese a Siviglia: collezionismo e influssi", en Dialogo artistico tra Italia e Spagna, ed. Marinella Pigozzi, (Bologna: Bononia University Press, 2018), pp. 27-38.

Japón 2020: Rafael Japón, "Guido Reni's influence in Seville through originals, copies and prints", en Artistic circulation between early modern Spain and Italy, ed. Kelley Helmstutler Di Dio y Tommaso Mozzati, (New York; Londres: Routledge, 2020), pp. 173-191.

Martínez 1866: Jusepe Martínez, Discursos practicables del nobilísimo arte de la pintura, ed. Valentín Carderera y Solano, (Madrid: Imprenta de Manuel Tello, 1866), pp. 120-121.

Santoyo 1972: Julio-César Santoyo, Viajeros por Álava (siglos XV a XVIII), (Vitoria: Obra Cultural de la Caja de Ahorros Municipal de Vitoria, 1972).

Štěpánek 2006: Pavel Štěpánek, "Španělská malba ze slovenských zbírek", Journal ARS, 39, (2006), pp. 53-76.

Valdivieso 2009: Enrique Valdivieso, "Pintura flamenca de los siglos XVI y XVII en Sevilla", en La senda española de los artistas flamencos, (Madrid: Fundación Amigos del Museo del Prado; Barcelona: Galaxia Gutenberg Círculo de Lectores, 2009), pp. 233-247.

Valdivieso 2018: Enrique Valdivieso, La escuela de Murillo. Aportaciones al conocimiento de su discípulos y seguidores, (Sevilla: Universidad de Sevilla, Ayuntamiento de Sevilla, ICAS, 2018).

Vlieghe 1972: Hans Vlieghe, Gaspar de Crayer, sa vie et ses oeuvres, (Bruselas: Arcade, 1972).

Recibido: 01/06/2021

Aceptado: 27/10/2021 
